Egypt. Acad. J. Biolog. Sci., 13(2):283-293 (2020)

Egyptian Academic Journal of Biological Sciences

A. Entomology

ISSN 1687- 8809

http://eajbsa.journals.ekb.eg/

\title{
Response of Peach Fruit Fly, Bactrocera zonata (Saunders) to the Essential Oil of Cubeb Pepper, Piper cubeba Bojer
}

\author{
El-Gendy, Ismail ${ }^{1}$, Nassar, Atef ${ }^{2}$ and Abdel-Hafeez, Tarek ${ }^{1}$ \\ 1- Plant Protection Research Institute, Agriculture Research Center, Giza, Egypt \\ 2-Department of Plant Protection, Faculty of Agriculture, Damanhour University, \\ Damanhour, El-Beheira, Egypt \\ Email:Ismail.El-Gendy@arc.sci.eg- atef.nassar@dmu.edu.eg-Tarek.Abdel-hafeez@arc.sci.eg
}

\begin{abstract}
ARTICLE INFO
Article History

Received:27/4/2020

Accepted: 5/6/2020

Keywords:

Fruit fly, sex

attractants, essential

oils, GC-MS, pest

management.

ABSTRACT

Peach fruit fly, Bactrocera zonata (Fam: Tephritidae, or: Diptera), is a quarantine insect-pest that infests various commercial fruit and vegetable crops in Egypt. Almost all the monitoring and control strategies of this fly depend on the use of the para-pheromone methyl eugenol (ME) as a sex attractant of male flies. Therefore, the current study aimed to investigate the potential use of the essential oil of berries of cubeb pepper (tailed pepper) (CEO), Piper cubeba (Fam: Piperaceae) as an attractant for B. zonata flies. CEO was extracted using the hydro-distillation scavenging apparatus from cubeb berries and chemically analyzed by GC-MS. The CEO was assayed in the attraction of B. zonata flies compared with the recommended dose of para-pheromone ME. Results showed that $\mathrm{ME}$ and the $\mathrm{CEO}$ at the different concentrations had attracted male flies and no females. Remarkably, there were no significant differences between ME and crude CEO in attracting the male flies. The GC-MS results revealed about 29 major constituents of CEO; the eugenol was the major constituent $(45.88 \%)$ of the CEO, followed by 3-methyl-pentane (15.36\%), methyl-cyclopentane (9.198\%), and methyl eugenol $(6.093 \%)$. These findings explaine the effective role of CEO as a male attractant of $B$. zonata and it could be used as an alternative to the ME, which would conserve a huge amount of money spent on buying the chemical ME.
\end{abstract}

\section{INTRODUCTION}

The essential oils of plants perform a variety of functions in the control of insect-pests and could be biologically active for insects as attractants, repellents, and toxicants (Isman 2000). Piper species (as P. nigrum L) have been recorded as insecticidal agents or seed protectors (Bernard et al., 1995; Scott et al., 2004). Also, P. nigrum extracts might provide a degree of protection against the larvae of lepidoptera and European pine sawfly and can also act as a repellent and anti-feeding agent (Scott et al., 2004).

The attractive component of citronella oil to males of Bactrocera dorsalis was found to be methyl eugenol (3-4 dimethoxy-1 allylbenzene) (Howlett 1915). Sixty years later, ME was documented as the most attractant for the oriental fruit fly, B. dorsalis, compared with 34

Citation: Egypt. Acad. J. Biolog. Sci. (A. Entomology) Vol. 13(2) pp: 283-293(2020) 
chemical analogs (Metcalf et al. 1975). This lure was used to monitor a wide range of the Dacinae flies as well as to control and eradicate male flies via male annihilation technique (Metcalf 1990; Metcalf and Metcalf 1992; Verghese et al., 2012; El-Gendy and Nassar 2014). The ME interfers with the insects' pheromone communication system physiologically and/or behaviourally (Renou and Guerrero 2000), where it affects the olfactory system with a phagostimulatory action of tephritid fruit flies with a powerful attraction extended to a distance of $800 \mathrm{~m}$ (Roomi et al., 1993; Bhagat et al., 2013; Haq et al., 2014).

Some plant species of the family Piperaceae are rich in ME and eugenol compounds (Tan and Nishida 2012) of which genus of Piper that has varied quantities of ME from 0.1 to more than 90\% of essential oils (De Vincenzi et al., 2000; Tan and Nishida, 2012). Cubeb pepper or tailed pepper (Piper cubeba Bojer) is a member of Family Piperacea, Genus Piper, which is mostly grown in Indonesia in Java and Sumatra islands as well as southern of India (Elfahmi et al., 2007). P. cubeba is widely used in the Egyptian kitchen as food spice and as a main ingredient of soup in many West African countries (Juliani et al., 2013). Additionally, $P$. cubeba used as a medicinal plant to treat dysentery, syphilis, gonorrhea, pain, diarrhea, enteritis and asthma, and unani (Graidistet et al., 2015). However, the usage of natural ME in the agricultural sector has not been spread.

In Egypt, the peach fruit fly, B. zonata (Diptera: Tephritidae) is a significant insect pest in horticultural crops (El-Gendy and El-Saadany 2012). That management strategies as the male annihilation technique were employed, it relies on the use of the ME as a males' lure, where males of B. zonata are strongly attracted to ME (Verghese et al., 2006; Bajaj and Singh 2018). To the best of our knowledge, no data are available about the use of essential oil of $P$. cubeba (CEO) in the attraction of $B$. zonata fly. Therefore, present study was conducted to evaluate the response of $B$. zonata flies for the $\mathrm{OE}$ of $P$. cubeba as a natural attractant substance under field conditions, as well as to identify the chemical constituents of the CEO using the gas chromatography-mass spectrometry (GC-MS).

\section{MATERIALS AND METHODS}

\section{Plant Material:}

Dry cubeb berries, $P$. cubeb, were purchased from the spice market in the Damanhour city of Egypt in 2019. The cubeb samples were re-recognized in the Department of Botany, Faculty of Agriculture, Damanhour University, Damanhour, El-Beheira, Egypt.

\section{Extraction of Essential Oil:}

The CEO was extracted by the hydro-distillation method using the oil scavenger according to Elyemni et al. (2019) at the Laboratory of Pesticides Residue Analysis and Toxicity (PRATL), Faculty of Agriculture, Damanhour University, Damanhour, El-Beheira, Egypt. Cubeb berries were grinded to a fine powder and a quantity of $200 \mathrm{~g}$ of cubeb powder was added to $800 \mathrm{ml}$ of distilled water in a 2-liter flask and heated for 3-4 hrs until no more oil condensed in the scavenger. By the end of the distillation, two phases were detected, the aqueous phase (aromatic water) and the organic phase (essential oil), which has less denisty than the water. The essential oil was collected and stored in dark bottles, at $4^{\circ} \mathrm{C}$, until being analyzed and tested against B. zonata.

\section{GC-MS Analysis Of Cubeb Essential Oil:}

About $1 \mu \mathrm{l}$ was taken from the CEO and analysed by Gas Chromatography-Mass Spectrometry (GC-MS) coupled with Varian 8200 autoinjector. The GC-MS semi-quantitative analysis was performed using the Agilent 7890A Gas Chromatography apparatus coupled with an Agilent 5975B mass selective detector (GC-MS) that equipped with an HP-5 capillary column $(30 \mathrm{~m} \times 0.25 \mathrm{~mm}$ ID, film thickness $0.25 \mu \mathrm{m}$, Agilent Technologies, USA). Separation of chemical components was completed at the following conditions: initial column temperature 
set at $50^{\circ} \mathrm{C}$ for $6 \mathrm{~min}$. It was increased to $215^{\circ} \mathrm{C}$ at $15^{\circ} \mathrm{C} / \mathrm{min}$ (hold for $1 \mathrm{~min}$ ), then to $230^{\circ} \mathrm{C}$ at $5^{\circ} \mathrm{C} / \mathrm{min}$, and finally to $290^{\circ} \mathrm{C}$ at $5^{\circ} \mathrm{C} / \mathrm{min}$ (hold for $2 \mathrm{~min}$ ). The solvent delay was kept 4 min, while the injector temperature was used at $250{ }^{\circ} \mathrm{C}$ and helium gas was the carrier. Electron ionization mass spectra were recorded up to $800 \mathrm{~m} / \mathrm{z}$ at $70 \mathrm{eV}$ with the ion source temperature at $230^{\circ} \mathrm{C}$. The GC-MS apparatus was controlled by a computer system, which has EI-MS libraries. The compounds in CEO were identified by the full mass spectra scans and retention time using their total ion chromatograms (TIC). The full scan mode allowed the contrast of the spectrum of obtained compounds with the EI-MS database libraries including NIST14 and Willey9.

\section{Study Area:}

The field experiments were conducted in Damanhour City, El-Beheira Governorate, Egypt. Experiments were carried out in two densely populated sites of B. zonata (according to preliminary tests of trapped flies). The first site has about 5 Feddans cultivated with papaz, loquat, guava, navel orange, sour orange, and palm trees, the second location has 3 Feddans cultivated with guava and navel orange. The distance between the two sites is about $1000 \mathrm{~m}$.

\section{Attraction Activity of CEO of B. zonata Fly:}

Assay of the CEO activity in the attraction of $B$. zonata flies depended on monitoring the population of adult insects of B. zonata. Inspection of the presence of B. zonata was conducted through September $1^{\text {st }}$ to December $1^{\text {st }}, 2019$ using Jackson traps (Haris et al., 1971). Traps were baited with CEO in four different concentrations; T1 (100\%), T2 (80\%), T3 $(66.66 \%)$, and T4 (50\%) of crude oil and the para-pheromone ME (T5) (98\%, manufactured by Sinoway International, Jiangsu, Co. LTD-China) (Table 1). The CEO concentrations were prepared by mixing the crude CEO with paraffin oil (v : v). Approx., $0.4 \mathrm{ml}$ of the tested treatments were injected in cylindrical cotton wicks $(1 \mathrm{~cm}$ height $\times 0.5 \mathrm{~cm}$ diameter). The traps were hung up on the trees' canopy at 1.5-2 m above the ground at a distance of about $50 \mathrm{~m}$ apart (El-Gendy 2012) in a randomized block design (CBD). Traps were repeated five times per treatment. Traps were examined every seven days and the cotton wicks were renewed once a month. Trapped flies were recognized, counted, recorded by sex, and expressed as the number of capture flies/trap/day (CTD) per each site, and means were considered in the analysis.

Table 1: Description of treatments used in lure traps against Bactrocera zonata males

\section{Treatment}

Description
Concentration (\%)

\begin{tabular}{cll}
\hline T1 & cubeb oil (crude oil) & 100.0 \\
\hline T2 & 1 vol (paraffin oil) $:$ 4 vol ( cubeb oil) & 80.00 \\
\hline T3 & 1 vol (paraffin oil) $:$ 2 vol ( cubeb oil) & 66.66 \\
\hline T4 & 1 vol (paraffin oil) $:$ 1 vol ( cubeb oil) & 50.00 \\
\hline T5 & Para-pheromone- ME (methyl eugenol) & 98.00 \\
\hline
\end{tabular}

\section{Statistical Analysis:}

Statistical analyses of the field data were achieved using CoStat (CoHort software, USA). The data were transformed to $\ln (\mathrm{x}+1)$ to reduce the heterogeneity of variances and analyzed with ANOVA; One-way randomized blocks with repeated measures and means were compared using the LSD test. Spearman's correlation $(\rho)$ was performed. 


\section{RESULTS AND DISCUSSION}

\section{1-Attractivness of CEO for B. zonata fly:}

$\mathrm{ME}$ and CEO were assayed in the attraction of $B$. zonata flies under field conditions using Jackson traps. Results showed that the ME and CEO trapped male flies only, no females were detected in all tested treatments (lures) (Table 2). Trapped male flies differed significantly among treatments $(\mathrm{F}=18.893, \mathrm{p}=0.0004)$ and lure longevity (exposure time) $(\mathrm{F}=64.16, \mathrm{p}=$ 0.0000). Additionally, highly significant interaction was reported between longevity of lures and treatments $(\mathrm{F}=4.70, \mathrm{p}=0.0003)$, with a significant impact (treatments; regreression slop $=$ $0.09, t=0.02, p=0.000 * * *$, lur longivety; regreression slop $=-0.17, t=-6.22, p=0.000 * * *)$ of $51.88 \%$ of total variance that affecting the captured male flies according to adjusted determenation coefficient (adj $\mathrm{R}^{2}$ ). As shown in Table 3, T1-treatment (crude CEO) exhibited more attraction of B. zonata males with 0.84 -fold of that in T5-treatment (ME, reference lure), however, no significant difference was reported between them. The T2-treatment was the $2^{\text {nd }}$ in the efficacy of males' attraction, followed by T4 and T3 treatments with $0.80,0.69$, and 0.61-fold of that in T5-treatment, respectively. However, no significant differences were found among T1, T4, and T2 treatments. Noticeable, the treatment T3 was the least in the attraction of $B$. zonata males and was not significantly different of T4. Previous results reported that ME attracted only male insects of B. zonata, B. dorsalis, and B. umbrosa (Kumar 2011; Tan 1985; Tan and Jaal 1986; Tan and Nishida 2012; Tan and Serit 1988, 1994). Besides the attraction of the males only of $B$. zonata and B. dorsalis to ME, B. correcta (Bezzi) males attracted to ME too (Verghese et al., 2006, Bajaj and Singh 2018). Also, the male adults of B. correcta flies attracted to traps containing ME, $\beta$-caryophyllene (Wee et al., 2017). However, Verghese (1998) mentioned that both males and females of $B$. dorsalis flies were attracted by ME. In addition, the $B$. dorsalis and $B$. correcta females attracted to $\beta$-caryophyllene (Jaleela et al., 2019). Also, the essential oils of angelica, ginger root, manuka, orange, cubeb, and tea tree plant were found to be attracted to males of Ceratitis capitata, when undiluted oil ( $5 \mu \mathrm{l})$ was tested (Epsky and Niogret 2017).

Table 2: Detected flies of Bactrocera zonata (males and females) using Jackson traps baited with different concentrations of cubeb essential oil (CEO) and para-pheromone ME (a reference).

\begin{tabular}{|c|c|c|c|c|c|c|c|c|}
\hline \multirow{3}{*}{ Treatment } & \multicolumn{9}{|c|}{ Detected flies } \\
\cline { 2 - 11 } & \multicolumn{9}{|c|}{ Date (week) } \\
\cline { 2 - 10 } & \multicolumn{2}{|c|}{1} & \multicolumn{2}{|c|}{2} & \multicolumn{2}{c|}{3} & \multicolumn{2}{c|}{4} \\
\cline { 2 - 10 } & 0 & + & 0 & + & 0 & + & 0 & + \\
\hline T1 & + & - & + & - & + & - & + & - \\
\hline T2 & + & - & + & - & + & - & + & - \\
\hline T3 & + & - & + & - & + & - & + & - \\
\hline T4 & + & - & + & - & + & - & + & - \\
\hline T5 & + & - & + & - & + & - & + & - \\
\hline
\end{tabular}

$\widehat{\jmath}:$ male flies, + : female flies, $+:$ detected, $-:$ not detected 
Table 3: Mean of captured male flies of Bactrocera zonata using Jackson trap baited with cubeb essential oil (CEO) and methyl eugenol (ME).

\begin{tabular}{|c|c|c|c|c|c|}
\hline \multirow{2}{*}{ Treatment } & \multicolumn{5}{|c|}{ Mean captured male flies/trap ( \pm SE) } \\
\cline { 2 - 6 } & \multicolumn{5}{|c|}{ Date (week) } \\
\cline { 2 - 6 } & 1 & 2 & 3 & 4 & Overall mean \\
\hline T1 & $1.67 \pm 0.02$ & $1.56 \pm 0.04$ & $1.08 \pm 0.13$ & $0.84 \pm 0.21$ & $1.29 \pm 0.12^{\mathrm{ab}}$ \\
\hline T2 & $1.42 \pm 0.03$ & $1.27 \pm 0.05$ & $1.20 \pm 0.015$ & $1.02 \pm 0.04$ & $1.23 \pm 0.04^{\mathrm{b}}$ \\
\hline T3 & $1.01 \pm 0.03$ & $1.07 \pm 0.02$ & $0.83 \pm 0.74$ & $0.82 \pm 0.04$ & $0.93 \pm 0.03^{\mathrm{c}}$ \\
\hline T4 & $1.38 \pm 0.02$ & $0.99 \pm 0.03$ & $1.05 \pm 0.04$ & $0.76 \pm 0.08$ & $1.05 \pm 0.07^{\mathrm{bc}}$ \\
\hline T5 & $1.77 \pm 0.02$ & $1.59 \pm 0.11$ & $1.57 \pm 0.09$ & $1.18 \pm 0.15$ & $1.53 \pm 0.08^{\mathrm{a}}$ \\
\hline Overall mean & $1.45 \pm 0.09^{\mathrm{a}}$ & $1.29 \pm 0.07^{\mathrm{ab}}$ & $1.15 \pm 0.06^{\mathrm{bc}}$ & $0.93 \pm 0.09^{\mathrm{c}}$ & $1.20 \pm 0.04$ \\
\hline
\end{tabular}

Means followed by the same superscript letter(s) are not significantly different according to Student's Neuman post-hoc multiple comparison method at $P \leq 0.05$. LSD 0.05 for overall mean treatments $=0.17, \mathrm{LSD}_{0.05}$ for overall mean dates $=0.15$.

The results revealed that responses of $B$. zonata males to CEO were concentrationdependent in a week direct relationship $\left(\rho=0.28, p=0.0045^{* *}\right)$. It was clear that the lure longivety was the most effective factor on the number of captured flies (regreression slop= $0.17, t=-6.22, p=0.000 * * *$ ) with $45.69 \%$ of total variance on $\mathrm{n}$ trapped males. Generaly, the decreased in numbers of trapped males with the decreasing of lure concentration of lure reported. These results were in agreement with the results of Dotterl et al. (2006), who mentioned that the responses of nursery pollinator, Hadena bicruris increased by increasing the concentrations of Silene latifolia that were diluted in paraffin oil. Ghanim (2013) reported that the weekly mean numbers of $B$. zonata males increased with an increased of MEconcentrations that were diluted in paraffin oil, where the higher mean number of males occurred significantly at the $100 \%$ concentration of ME. It is worth mentioning that paraffin oil that used as a solvent for the CEO had no effect on males' attraction.

Regarding the longevity of the tested lures (Fig. 1), the captured numbers of B. zonata males were inversely related to lure longevity, with a moderate negative correlation $(r=-54$, $\left.p=0.0001^{* * *}\right)$. The trapped males in T3-treatment reached its highest number on the $14^{\text {th }}$ day then were gradually decreased. Treatments of T1, T2, and T4 had caught high number of males at the $1^{\text {st }}$ week similar to T5. Afterwards, the numbers of trapped males were gradually declined with elapsed time. The decreasing pattern of male flies' numbers varied not only among treatments but also among investigated times. The decreasing numbers of males occurred in the treatments of T1 by $0.07,0.35$ and 0.50 -fold, T2 by $0.11,0.15$ and 0.28 -fold, T4 by 0.28 , 0.24 and 0.45 -fold, and T5 by $0.10,0.11$ and 0.33 -fold in the $2^{\text {nd }}, 3^{\text {rd }}$, and $4^{\text {th }}$ week, respectively of captured males at the $1^{\text {st }}$ week of the same treatment. Whilst the decrease in the trapped males of T3- treatment was 0.18 and 0.19 -fold in the $3^{\text {rd }}$ and $4^{\text {th }}$ week of males captured at the $1^{\text {st }}$ week. Noticeable, there were no significant differences in male catching at the $1^{\text {st }}, 2^{\text {nd, }}$ and $3^{\text {rd }}$ week whether in T1- or T5-treatment. These results were supported by that of Ghanim (2013), who mentioned that B. zonata males' numbers decreased with time along 10 weeks. 

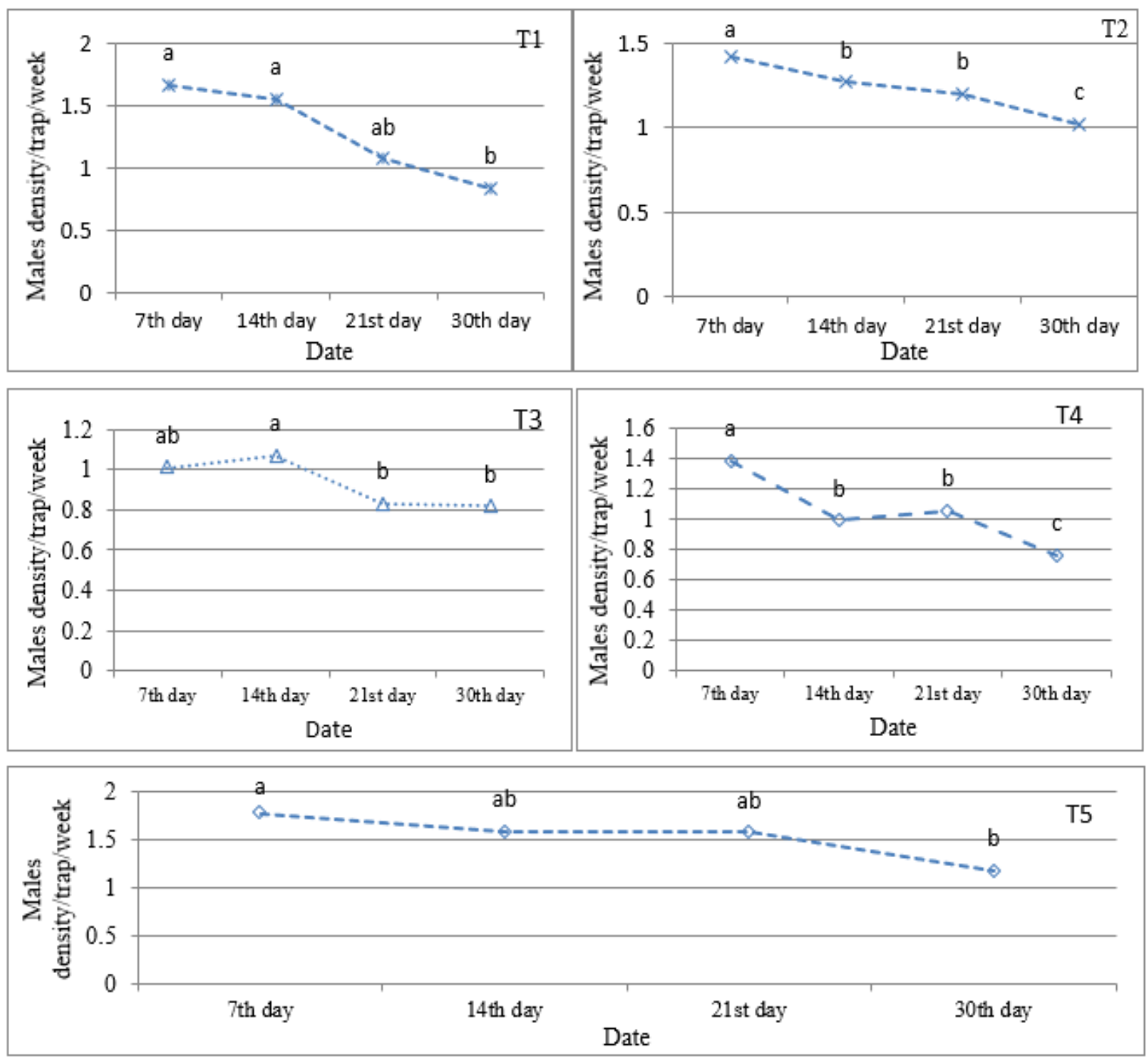

Fig.1: Mean captured numbers of male peach fruit fly, Bactrocera zonata, which were attracted by cubeb essential oil (CEO) concentrations (T1; 100\%, T2; 80, T3; 66.6, and T4; 50\% of crude oil) and methyl eugenol (ME; 98\%). LSD0.05 values were 0.55, 0.11, 0.20, $0.2,0.54$ for $\mathrm{T} 1, \mathrm{~T} 2, \mathrm{~T} 3, \mathrm{~T} 4$, and $\mathrm{T} 5$, respectively.

\section{2-CEO Volatile Components:}

The GC-MS analysis of the volatile composition of CEO was presented in Table 4 and Figure 2. GC-MS results revealed the presence in 29 chemical compounds of CEO. The dominant constituents that were identified as eugenol (phenol-2-methoxy-4(2-propenyl)) (45.88\%), followed by, 3-methyl-pentane (15.36\%), methyl-cyclopentane (9.198\%), methyl eugenol (1, 2-dimethoxy-4-(2-propenyl) benzene) (6.093\%), $\beta$-myrcene $(2.029 \%), \beta$ caryophyllene $(1.259 \%)$, and $\alpha$-copaene $(0.259 \%)$. The present findings revealed that the constituents of CEO were mainly eugenol and methyl eugenol. Also, the obtained results showed that the CEO is rich in eugenol compounds, which was reported as a source for omethyl eugenol (Herrmann and Weaver 1999). In the same line with the present findings, Cheng et al. (2018) reported that components of the oil of berries of P. cubeba, that were extracted using hydro-distillation (HDE) and simultaneous distillation extraction (SDE) and identified by GC-MS were similar to the obtained finding, especially methyl eugenol with traces amount of 0.71 and $0.11 \%$ by HD and SDE, respectively. Also, terpinen-4-ol (42.41\%), $\alpha$-copaene $(20.04 \%)$, and $\gamma$-elemene $(17.68 \%)$ were the major components of $P$. cubeba EO (Andriana et al., 2019). 
Table 4: Chemical components of cubeb essential oil (CEO), Piper cubeba as separated using GC-MS and identified using the chemical database libraries of NIST 14 and Willey 9.

\begin{tabular}{|c|c|c|}
\hline $\mathbf{R t}^{\mathbf{a}}$ (min) & Components & $\begin{array}{l}\text { Area of Total } \\
(\%)\end{array}$ \\
\hline 2.538 & 3-Methyl-pentane & 15.36 \\
\hline 2.787 & Methyl-cyclopentane & 9.198 \\
\hline 6.178 & $\alpha$-Pinene & 0.038 \\
\hline 6.980 & $\beta$-Myrcene & 2.029 \\
\hline 7.257 & $\alpha$-Phellandrene & 0.044 \\
\hline 7.444 & $\alpha$-Terpinene & 0.039 \\
\hline 7.572 & $p$-Cymene & 0.071 \\
\hline 7.637 & dl-Limonene & 0.123 \\
\hline 7.699 & Eucalyptol (1,8-Cineole) & 0.474 \\
\hline 7.868 & cis- $\beta$-Ocimene & 0.107 \\
\hline 8.092 & $\gamma$-Terpinene & 0.064 \\
\hline 8.564 & $\alpha$-Terpinolene & 0.095 \\
\hline 8.701 & Linalool & 0.110 \\
\hline 9.976 & Terpinen-4-ol & 0.130 \\
\hline 10.168 & $\alpha$-Terpineol & 0.609 \\
\hline 11.214 & Chavicol (4-Allylphenol) & 0.484 \\
\hline 12.445 & Eugenol & 45.88 \\
\hline 12.642 & $\alpha$-Copaene & 0.259 \\
\hline 12.854 & Methyl eugenol & 6.093 \\
\hline 13.178 & $\beta$-Caryophyllene & 1.259 \\
\hline 13.539 & $\beta$-Selinene & 0.229 \\
\hline 13.715 & $\gamma$-Muurolene & 0.036 \\
\hline 14.106 & $\alpha$-Cadina-4,9-diene & 0.023 \\
\hline 14.157 & $\Delta$-Cadinene & 0.098 \\
\hline 14.770 & Spathulenol & 0.053 \\
\hline 14.830 & Caryophyllene oxide & 0.185 \\
\hline 15.290 & $t$-Cadinol & 0.216 \\
\hline 15.446 & Aromandendrene & 0.214 \\
\hline 15.555 & iso-Aromadendrene epoxide & 0.072 \\
\hline
\end{tabular}

Rt: retention time

Also, similar results were obtained in other Piperaceae plants, where ME was detected in different ratios in Betel pepper that had 4.1-6.9\% of ME and 82.2-90.55\% of eugenol (Sharma et al., 1983). EOs of Piper divaricatum had ME (17-93\%) and eugenol (2-46\%) (Maia and Andrade 2009). Generally, the present results revealed that male flies of B. zonata attracted to traps baited with the different concentrations of CEO, accordingly, CEO acts as a male's lure to $B$. zonata. Furthermore, the CEO analysis revealed that chemical constituents were related to the chemical ME, of which eugenol (phenol-2-methoxy-4(2-propenyl)) and methyl eugenol (1, 2-dimethoxy-4-(2-propenyl) benzene). These results might be interpreting the attraction of $B$. zonata males to CEO, but further studies are needed. 


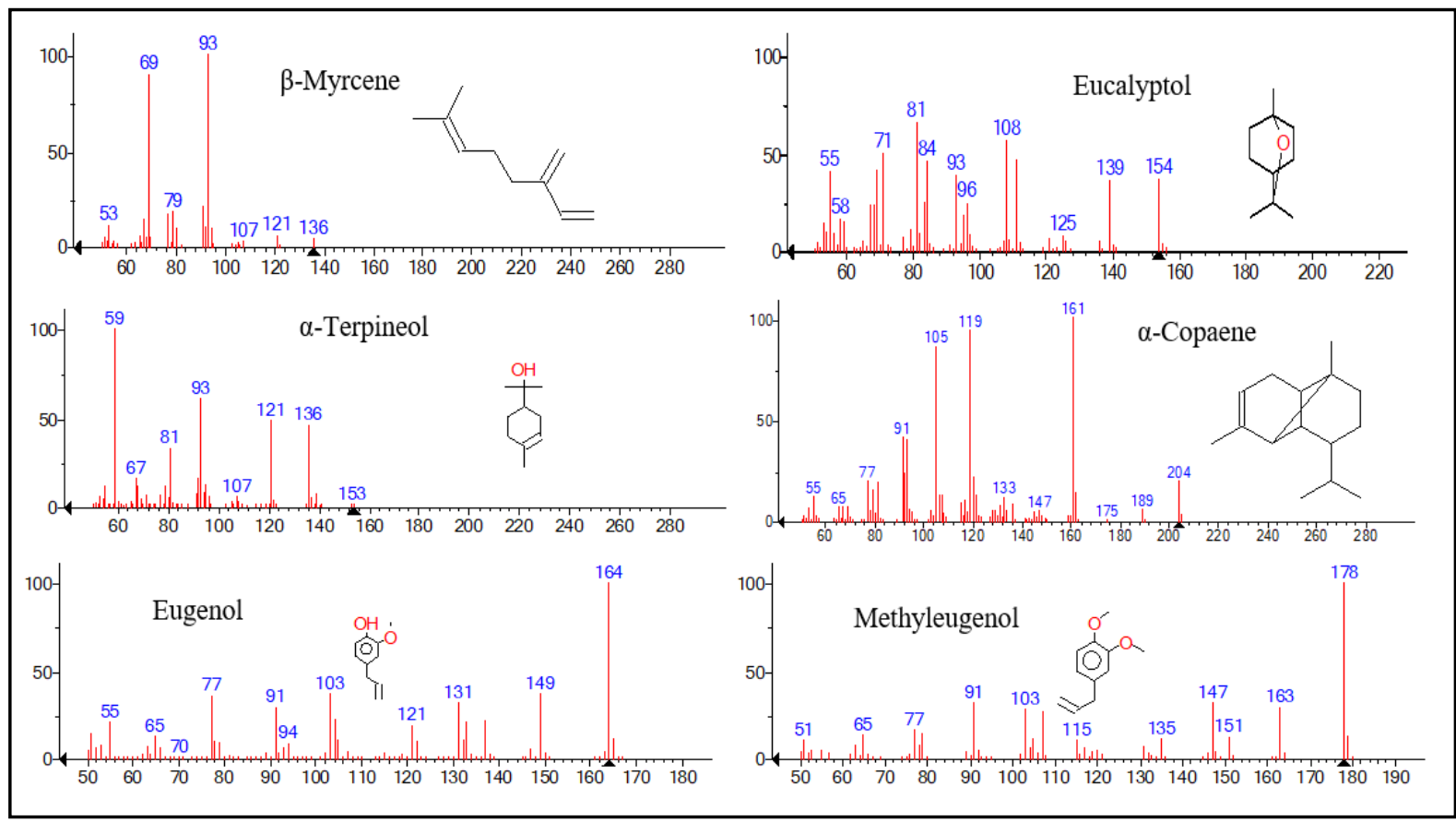

Fig. 2: Mass spectral pictograms of abundant chemical components in essential oil extract of cubeb berries (Piper cubeba) after analysis using GC-MS and identification using the NIST/EPA/NIH mass spectral library software version 2.2 build 2014

\section{REFERENCES}

Andriana, Y.; Xuan, T.D.; Quy, T. N.; Tran, H. and Quang-Tri, Le. (2019). Biological activities and chemical constituents of essential oils from Piper cubeba Bojer and Piper nigrum L. Molecules.1-16. DOI:10.3390/molecules24101876.

Bajaj, K. and Singh, S. (2018). Response of fruit flies, Bactrocera spp. (Diptera: Tephritidae) to different shapes of methyl eugenol based traps in guava orchards of Punjab. Journal of Entomology and Zoology Studies. 6: 2435-2438.

Bernard, C. B.; Krishnamurty, H.G.; Chauret, D.; Durst, T.; Philoge`ne, B.J.R.; SanchezVindas P.; Hasbun, C.; Poveda, L.; Roman, L.S. and Arnason, J.T. (1995). Insecticidal defenses of Piperaceae from the Neotropics. Journal of Chemical Ecology. 21: 801-814.

Bhagat, D.; Samanta, S.K. and Bhattacharya, S. (2013). Efficient management of fruit pests by pheromone nanogels. Scientific Reports. 3:1-8.

Cheng, H.; Chen, J.; Watkins, P.J.; Chen, S.H.; Wu, D.; Lui, D. and Ye, X. (2018). Discrimination of aroma characteristics for cubeb berries by sensomics approach with chemometrics. Molecules. 23,1627; DOI:10.3390/molecules 23071627.

Costat Software. 2008. CoHort Software. Version 6.4. Monterey, CA, USA.

De Vincenzi, M.; Silano, M.; Stacchini, P. and Scazzocchio, B. (2000). Constituents of aromatic plants: I. Methyleugenol. Fitoterapia. 71:216-221.

Dotter, S.; Jurgens, A.; Seifert, K. Laube, T.; Weissbecker, B. and Schutz S. (2006). Nursery pollination by a moth in Silene latifolia: the role of odours in eliciting antennal and behavioural responses. New Phytologist. 169:637-640.

Elfahmi; Ruslan, K.; Batterman, S.; Bos, R.; Kayser, O.; Woerdenbag. H.J.; Quax, W. J. (2007). Lgnan profile of Piper cubeba, an Indonesian medicinal plant. Biochemical Systematics Ecology. 35:397-402.

El-Gendy, I.R., and Nassar, A.M.K. (2014). Delimiting survey and seasonal activity of peach fruit fly, Bactrocera zonata and Mediterranean fruit fly, Ceratitis capitata Diptera: tephritidae) at El-Beheira Governorate, Egypt. Egyptian Academic Journal of Biological 
Sciences (A. Entomology) Vol. 7:157-169.

El-Gendy, I.R. (2012). Elevation of attraction efficiency of Jackson traps on Peach Fruit Fly, Bactrocera zonata (Saunders). International Journal of Agricultural Research. 7:223230.

El-Gendy, I.R. and El-Saadany, G.B. (2012).Monitoring the changes in the population dynamics of field generations of peach fruit fly, Bactrocera zonata and some factors affecting them under field conditions. Cairo International Conference for clean pest Management, Egypt. 12-13 November, 90:777-798.

Elyemni, M.; Louaste, B.; Nechad, I.; Elkamli, T.; Bouia, A.; Taleb, M.; Chaouch, M. and Eloutassi N. (2019). Extraction of Essential Oils of Rosmarinus officinalis L. by Two Different Methods: Hydrodistillation and Microwave Assisted Hydrodistillation. The Scientific World Journal. DOI: 10.1155/2019/3659432.

Epsky, N.D. and Niogret, J. (2017). Short range attraction of Ceratitis capitata (Diptera: Tephritidae) sterile males to six commercially available plant essential oils. Natural Volatiles \& Essential Oils. 4:1-7.

Ghanim, M. N. (2013). Influence of methyl eugenol diluted with paraffin oil on male annihilation technique of peach fruit fly, Bactrocera zonata (Saunders) (Diptera: Tephritidae). Entomology, Ornithology \& Herpetology. 2:1-6.

Graidist, P.; Martla, M. and Sukpondma, Y. (2015). Cytoxic activity of Piper cubeba extract in breast cancer cell lines. Nutrients. 7: 2707-2718.

Haq, I.; Vreysen, M.J.B.; Caceres, C.; Shelly, T. E. and Hendrichs J. (2014). Methyl eugenol aromatherapy enhances the mating competitiveness of male Bactrocera carambolae Drew \& Hancock (Diptera: Tephritidae). Journal of Insect Physiology. 68:1-6.

Harris, E.J.; Nakagawa, S. and Urago T. (1971). Sticky traps for detection and survey of three tephritids. Journal of Economic Entomology. 64:62-65.

Herrmann, K.M. and Weaver, L.M. (1999). The shikimate pathway. Annual Review of Plant Physiology and Plant Molecular Biology. 50:473-503.

Howlett, F.M. (1915). Chemical reactions of fruit flies. Bulletin of Entomological Research. 6: 297-305.

Isman, M.B. (2000). Plant essential oils for pest and disease management. Crop Protection. 19:603-608.

Jaleela, W.; Heb, Y. and Lüa L. (2019). The response of two Bactrocera species (Diptera: Tephritidae) to fruit volatiles. Journal of Asia-Pacific Entomology. 22:758-765.

Juliani, H.R.; Korch, A.; Giordanoug, L.; Amekuse, L.; Koffa, S.; Acquaye, D. and Simon, J.E. (2013). Piper Guineese (Piperacae): Chemistry, traditional uses and functional properties of an African black pepper. Acs Symposium Series. 1127:33-48.

Kumar, P. (2011). Field Exercise Guide on Fruit Flies Integrated Pest Management for Farmer's Field Schools and Training of Trainers Area-Wide Integrated Pest Management of Fruit flies in South and Southeast Asian Countries. Asian Fruit Fly IPM Project, Bangkok, Thailand. 63 pp.

Maia, J.G.S.; Andrade, E.H.A. (2009). Database of the Amazon aromatic plants and their essential oils. Quimica Nova. 32:595-622.

Metcalf, R.L. (1990). Chemical ecology of Dacinae fruit flies (Diptera: Tephritidae). Annals of Entomological Society of America. 83:1017-1030.

Metcalf, R.L. and Metcalf, E.R. (1992). Fruit flies of the family Tephritidae. In: Metcalf RL, Metcalf ER, Editors. Plant Kairomones in Insect Ecology and Control. pp. 109-152. Chapman Hall.

Metcalf, R.L.; Mitchell, W.C.; Fukuto, T.R. and Metcalf E.R. (1975). Attraction of the oriental fruit fly, Dacus dorsalis, by methyl eugenol and related olfactory stimulants. Proceedings of the National Academy of Sciences USA. 72:2501-2505. 
Renou, M. and Guerrero A. (2000). Insect pheromones in olfaction research and semiochemical based pest control strategies. Annual Review of Entomology. 45:605-630.

Roomi, M.W.; Abbas, T.; Shah, A.H.; Robina, S.; Qureshi, A.A.; Sain, S.S. and Nasir, K.A. (1993). Control of fruit flies (Dacus sp.) by attractants of plant origin. Anzeiger fiir Schadlingskunde, Pflanzeschutz, Umwelschutz. 66:155-157.

Scott, I.M.; Jensen, H.; Nicol, R.; Lesage, L.; Bradbury, R.; Sa' Nchez-Vindas, L.; Poveda, P.; Arnason, J.T.; Philoge' Ne, D.B.J.R. (2004). Efficacy of piper (piperaceae) extracts for control of common home and garden insect pests. Jornal of Economic Entomology. 97: 1390-1403.

Sharma, M.L.; Rawat, A.K.S.; Blalasubrhmanyam V.R. and Singh A. (1983). Studies on essential oil of betel vine leaf (Piper betle Linn.). Indian Perfumer. 27: 91-93.

Tan, K.H. (1985). Estimation of native populations of male Dacus spp. by Jolly's stochastic method using a new designed attractant trap in a village ecosystem. Journal of Plant Protection in the Tropics. 2:87-95.

Tan, K.H. and Jaal, Z. (1986). Comparison of male adult population densities of the Oriental and Artocarpus fruit flies, Dacus spp. (Diptera: Tephritidae), in two nearby villages in Penang, Malaysia. Researches on Population Ecology. 25:85-89.

Tan, K.H. and Serit M. (1988). Movements and population density comparisons of native male adult Dacus dorsalis and Dacus umbrosus (Diptera: Tephritidae) between three ecosystems in Tanjong Bungah, Penang. Journal of Plant Protection in the Tropics. 5: $17-21$.

Tan, K.H.; Nishida, R. (1996). Sex pheromone and mating competition after methyl eugenol consumption in the Bactrocera dorsalis complex. In: McPheron BA, Steck GJ (eds) Fruit fly pests: a world assessment of their biology and management. St. Lucid Press, Florida. pp 147-153.

Tan, K.H.; Nishida, R. (2012). Methyl eugenol: Its occurrence, distribution, and role in nature, especially in relation to insect behavior and pollination. Journal of Insect Science: Vol. 12| Article 56.

Tan, K.H.; Serit, M. (1994). Adult population dynamics of Bactrocera dorsalis (Diptera: Tephritidae) in relation to host phenology and weather in two villages of Penang Island, Malaysia. Environmental Entomology. 23:267-275.

Verghese, A. (1998). Methyl eugenol attracts female mango fruit fly, Bactrocera dorsalis Hendel.Insect environment 4:101.

Verghese, A.; Shinananda, T.N.; Hegde, M.R. (2012). Status and area-wide integrated management of mango fruit fly, Bactrocera dorsalis (Hendel) in South India. Lead paper. In: Ameta O P, Swaminathan R, Sharma U S and Bajpai N K (ed) Nat Sem Emerging Pest Problems Bio-Rational Mgmt. 2-3.

Verghese, A.; Sreedevi, K.; Nagaraju, D. K. and Jayanthi Mala B. R. (2006). A farmer-friendly trap for the management of the fruit fly Bactrocera spp. (Tephritidae: Diptera). Pest Management in Horticulture Ecosystems. 12:164-167.

Wee, S.L.; Chinvinijkl, S.; Tan, K.H. and Nishida, R. (2017). A new and highly effective male lure for the guava fruit fly Bactrocera Correcta. Journal of Pest Science. 91: 691-698. DOI: $10.1007 /$ S10340-017-0936-Y.

$\mathrm{Xu}, \mathrm{Z}$. and Deng, M. (2017). Identification and control of common weeds. Springer Netherlands. ISBN 978-94-024-1157-7, Vol 2 pp. 115-118. 


\section{ARABIC SUMMARY}

استجابة ذبابة ثمار الخوخ Saunders) Bactrocera zonata للمستخلص الزيتى لثمار نبات الكبيبة Piper cubeba

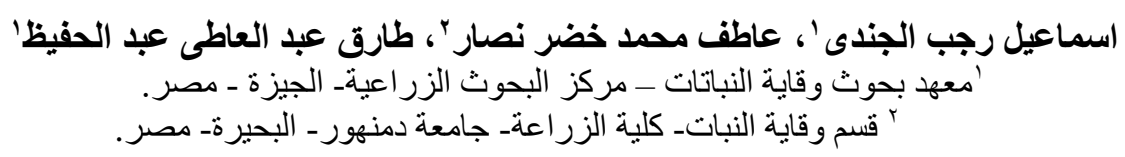

ذبابة ثمار الخوخ Fam: Tephritidae: Diptera) Bactrocera zonata) هي آفة حشرية حجرية تصيب

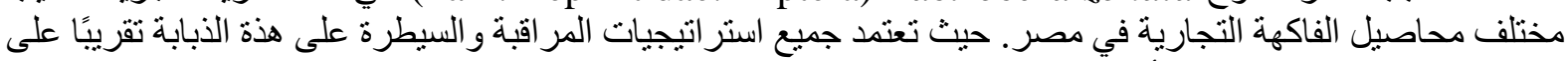

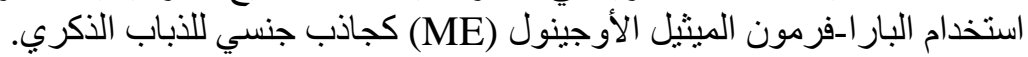

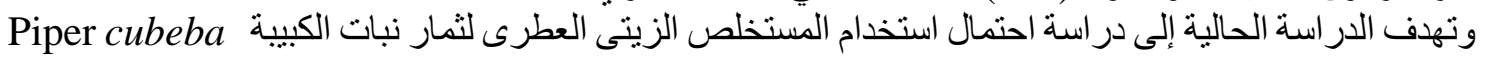
كجاذب لذبابة ثمار الخوخ .Bonata حيث نم استخلاص زيت الكبيبة باستخدام جهاز المسح بالثقطير المائي لثمار نبات الكبيبة،

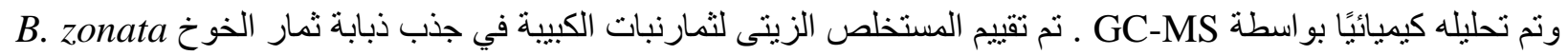

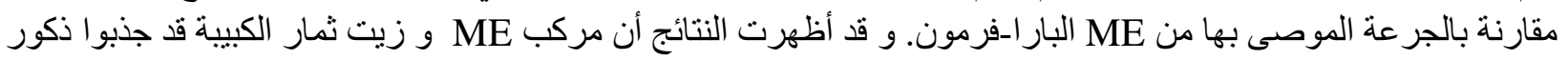

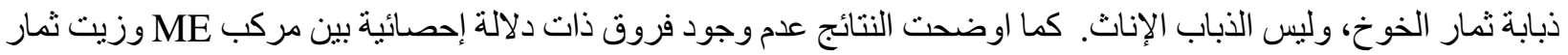

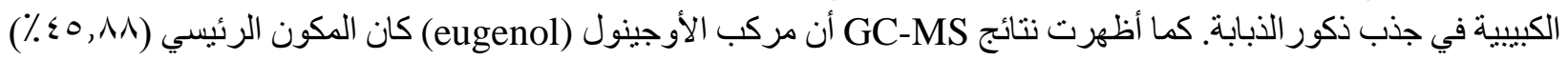

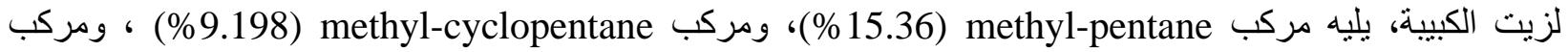
، B. zonata methyl eugenol ويمكن استخدامه كبديل للمركب الكيماوى ME ، والذي سيوفر مبلغًا كبيرًا من الأمو ال التي يتم إنفاقها على شر اء المادة الكيميائية. 